\title{
Expectations of Fundamental Knowledge in a Commercial Space Education Program by Space Industry Professionals and Aeronautical Engineering Technology Students
}

\section{Dr. Sergey Dubikovsky, Tracy L. Yother, J. M. Thom, Jack C. Dozier, Alisha Garcia, Thomas Agler, Joseph Friedl, Nick Koehler, and Connor Hagan}

\author{
Purdue University
}

\begin{abstract}
Career opportunities in the space industry are growing due to a combination of both the growth of the industry projected by the department of U.S. Labor Statistics and the age of existing employees. A new source of skilled workers is needed during this growth to ensure that companies can continue to develop quality designs, manufacturing, and production of the next generation spacecraft. One source to meet this need is the evolution of existing aerospace focused programs, such as Aeronautical Engineering Technology (AET). However, the transformation of any program must include an understanding of the new requisite and fundamental skills and unique requirements. This research includes a survey of space industry professionals to establish baseline commercial space industry knowledge. In addition, a survey of existing AET students is included to examine the difference between student and industry expectations. The results are combined to generate a ranked list of minimal knowledge expected by industry for recent graduates of a space focused AET program.

In addition, a comparison to what students expect versus professional realities is important to understand. This insight facilitates recruitment into the profession and enhances student retention and satisfaction. These concepts can and should be included in curriculum and course development to bring the meaningful relevance of information for the students as they learn. Inclusion also provides the student both context and a springboard for industry expectations.
\end{abstract}

\section{Introduction}

The commercial space industry is a new and growing industry in the aerospace sector. NASA's move toward outsourcing much of their routine rocket launches to the International Space Station (ISS) provides an opportunity for private companies to participate in the space industry in a manner previously unavailable to them. However, this opportunity is neither simple nor easy. Since commercial space companies are relatively new entities they must build their infrastructure, which includes personnel.

The challenge of developing personnel begins with understanding what skills should be cultivated. Having the right set of skills can make a significant difference to a candidate for the desired position.

\section{Research Background}

This research is an outgrowth of a senior design course of AET students at Purdue University led by Dr. Sergey Dubikovsky. The research, unique to this cohort of students, and a fellow professor and researcher on this project, Professor J. M. Thom, requested this particular topic. Anecdotal 
evidence leads him to believe an opportunity existed to both provide additional training to AET students to supply trained individuals to the commercial space industry for employment. This belief is supported by a confidential source from a commercial spacecraft company who indicated that new commercial space industry managers are not interested in hiring traditional space industry workers due to the potential inflow of negative legacy issues from 50 years of the first generation space industry (J.M. Thom, personal communication, October 28, 2010).

\section{Occupational Outlook}

\section{Review of Literature}

The size of the commercial space industry is large enough to become noteworthy, based on 2014 figures from the Federal Aviation Administration the launch events "amounted to approximately $\$ 2.36$ billion. The opportunities for a recent graduate or upward mobility in this industry are present for those who are interested.

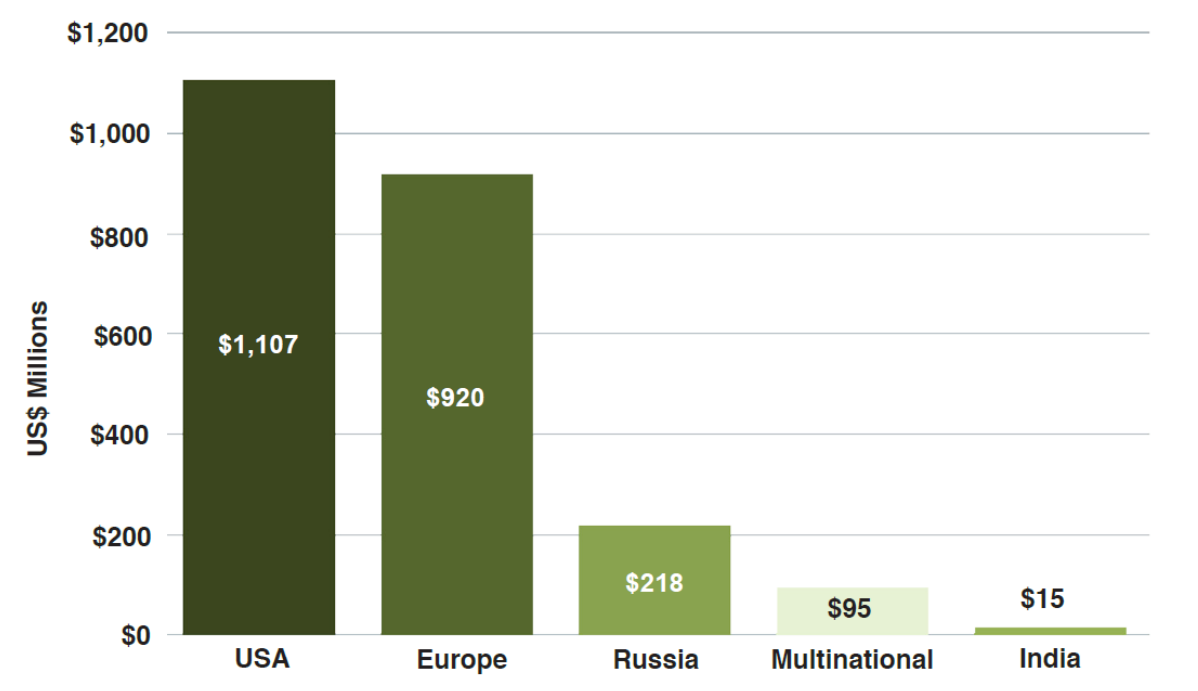

Figure 1. Estimates 2014 Commercial Launch Revenues

There are two main pathways for expansion in the commercial space industry. The first is focused on the expansion of the industry. According to the U.S. Bureau of Labor Statistics Occupational Outlook Handbook, "Employment of aerospace engineering and operations technicians is projected to grow 4 percent from 2014 to 2024" (U.S. Labor Statistics, 2017). Deloitte (2016, 2017) forecasted growth of the global aerospace and defense sector to be around 3 percent in 2016 and 2 percent in 2017. According to the same sources, defense subsector revenues will increase 3.2 percent in 2017 because of growing defense spending in the US. An analysis of a survey performed by Forbes Insights in 2016 showed that growth prospects are expected in the near future. In the course of the survey, almost 66 percent of 76 senior aerospace and defense executives expressed confidence that their companies will grow in next two years. Interviews with leading aerospace and defense experts (KPMG International, 2016) supported the results of the survey, which were included in the same study. While the expansion is not as high as some would like to see, it is still a growing market. 
According to the Federal Aviation Administration's (2014) report, the number of launches is anticipated to hold steady for at least the next 10 years, see Table 1.

Table 1. Forecast Commercial GSO Satellite and Launch Demand

\begin{tabular}{|c|c|c|c|c|c|c|c|c|c|c|c|c|c|}
\hline & 2014 & 2015 & 2016 & 2017 & 2018 & 2019 & 2020 & 2021 & 2022 & 2023 & Total & Avg \\
\hline Satellite Demand & 18 & 25 & 24 & 23 & 22 & 23 & 23 & 22 & 23 & 23 & 226 & 22.6 \\
\hline Launch Demand & 13 & 18 & 19 & 16 & 16 & 16 & 17 & 15 & 17 & 16 & 163 & 16.3 \\
\hline $\begin{array}{c}\text { Dual Launch } \\
\text { Demand }\end{array}$ & 5 & 7 & 5 & 7 & 6 & 7 & 6 & 7 & 6 & 7 & 63 & 6.3 \\
\hline
\end{tabular}

The second pathway focuses on the rapid retirements of existing space workers, the "so-called silver tsunami" (Zillman, 2013). Interestingly, the space industry is a contributing source of the labor problems facing the industry today. Over half of the aerospace workers of today have joined the industry as a result of the inspiration of the race to the moon (Zillman, 2013). The age of those workers is now reaching that which makes them eligible for retirement.

Aging workers are not a new phenomenon for the aerospace industry. The industry has been working through this challenge for almost a decade, and in fact, made progress in avoiding losing their experienced workforce all at once. Figure 2 below shows a reduction in the age of its workers since 2010. In fact, the average age is stable at 47 years old and has been since 2012 (Aviation Week Network, 2016, p. 11).

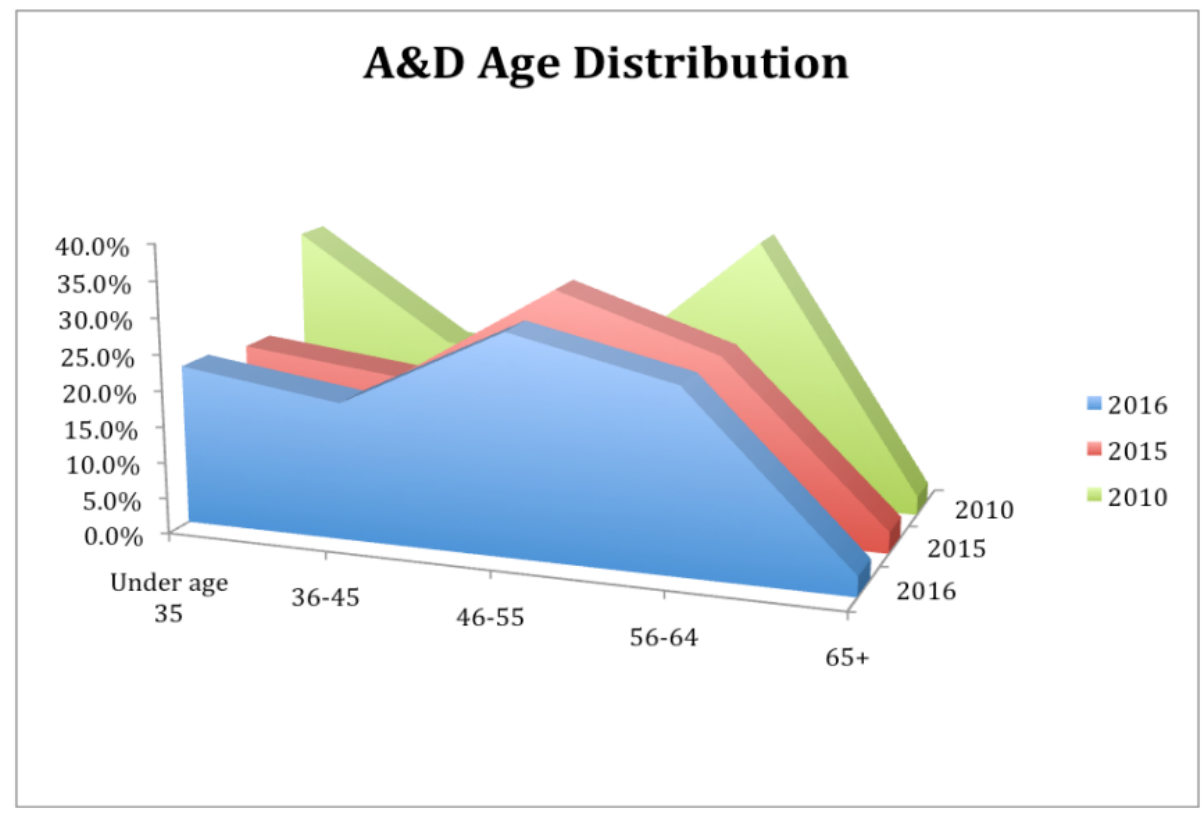

Figure 2 Aerospace and defense age distribution

Regardless of the work that has been done, the issue of age in the workforce is still problematic for the industry. According to the U.S. Government Accountability Office (2014), "Aviation stakeholders have expressed concern that an insufficient supply of certain types of aviation 
professionals-aerospace engineers, aircraft mechanics, and avionics technicians-could develop because of imminent retirements..." (p. 1). The workforce is aging, and replacement workers are needed to not only replace the aging workers, but more importantly, learn from them before they retire.

\section{Purpose of Study}

In order to understand the needs of the industry, this research is designed to answer two questions. The first question is what knowledge and skills do current commercial space industry professionals desire in candidates for employment? Second, what expectations do current students in AET have in a space focused curriculum?

\section{Design of Study}

To assess what key topics are applicable, current commercial space industry alumni were contacted and provided with two surveys. These same two surveys were then distributed to Purdue University AET undergraduate students. All responses were recorded and organized by average number participant responses.

\section{Survey Instruments}

The first survey (see Appendix A for a copy of survey \#1) were given to both industry alumni and undergraduate students was designed to collect three pieces of information. The first allowed the participants to rate themselves on their personal level of experience and interest in the space industry. Participants ranked themselves on a scale 1-5, 1 having no experience and 5 having the most experience. The second piece was a list of personally important topics related to success in the space industry. The final question asked participants to choose a course administration model (i.e. lab and lecture vs. lecture and no lab).

Results from the first survey were used to develop the second survey tool. The second survey (see Appendix B for a copy of survey \#2) provided participants a list of 25 topics found to be significant in the space industry. Using a scale of 0-5 (0 being not important and 5 being very important), participants rated each topic by what they felt was its own level of importance. Topics that participants thought were very important received 5's, while topics they felt had no importance to the space industry received 0 .

\section{Participants}

The participants of this study consisted of 80 students from the AET undergraduate program and 4 space industry AET alumni. The survey results were anonymous and voluntary for all participants. Students participants ranged from the freshman to seniors, spread out through three different courses. The alumni participants were actively employed at four different companies that were involved in space/space technologies. For the purposes of our survey and the preferences of our alumni, their names and their company names were kept confidential. 


\section{Survey Results}

\section{Survey 1}

The participants in survey 1 were 41 underclassmen, 39 upperclassmen, and four alumni from industry. All were asked to rate their personal experience in the space industry using the scale identified in Table 1. Although the research team expected all alumni participating in the survey rated themselves as a five, they were asked to rate their personal level of experience to prevent partiality. The results gathered from question one were measured using percentages as shown in Table 3.

Table 2. Individual ranking of personal experience in the space industry

\begin{tabular}{|c|c|}
\hline 1 & I have no prior knowledge about space/space technology \\
\hline 2 & $\begin{array}{l}\text { I understand some concepts about space/space technology, but have not worked/studied with any space related } \\
\text { classes }\end{array}$ \\
\hline 3 & I have studied some aspects about space/space technology in a classroom environment or from personal interest \\
\hline 4 & $\begin{array}{l}\text { I regularly read space related publications, have participated on a space related class project, and/or study space } \\
\text { related materials }\end{array}$ \\
\hline 5 & $\begin{array}{l}\text { I have had an internship/job with a company involved in space and/or have worked with space materials on a } \\
\text { university level class project }\end{array}$ \\
\hline
\end{tabular}

Table 3. Percentage breakdown of the results of question 1 in survey 1

\begin{tabular}{|c|c|c|c|}
\hline Ratings & Underclassmen & Upperclassmen & Industry \\
\hline \hline 1 & $9.8 \%$ & $7.7 \%$ & $0 \%$ \\
\hline 2 & $48.8 \%$ & $33.3 \%$ & $0 \%$ \\
\hline 3 & $31.7 \%$ & $46.2 \%$ & $0 \%$ \\
\hline 4 & $7.3 \%$ & $12.8 \%$ & $0 \%$ \\
\hline 5 & $2.4 \%$ & $0 \%$ & $100 \%$ \\
\hline
\end{tabular}

Question 2 in survey \#1 asked participants to list topics they felt were most important to succeed in the space industry; results are found in Table 4. The results from survey \#1 were used to build survey \#2. 
Table 4. Top 5 topics seen most frequently from the participants

\begin{tabular}{|c|c|c|}
\hline \multicolumn{3}{|c|}{ Top 5 Important Topics to Succeed in Industry } \\
\hline Underclassmen & Upperclassmen & Industry \\
\hline Physics & Physics & Rocket Propellants/Hazards \\
\hline Technology & Astronomy & Propulsion Systems \\
\hline Mathematics & Fuels & $\begin{array}{c}\text { Management and Testing } \\
\text { Facilities }\end{array}$ \\
\hline Astronomy & Technology & Project Management \\
\hline Aerodynamics & Propulsion & Orbital/Rocket Science \\
\hline
\end{tabular}

\section{Survey 2}

Rated by alumni and undergraduates, survey 2 was designed to show if there was a gap in knowledge of the students, compared to the industry.

Figure 3 shows the ratings of the 25 topics grouped by industry and students.

\section{Survey Discussion}

This research was intended to understand the needs of industry, the expectations of students, and, possibly, more importantly, understanding the differences between the two. In order to build a successful commercial space program, the expectations of both groups needed to be met. The industry needed graduates who met their needs. It was also believed that if students entered a program that did not cover anticipated topics the disconnect could result in retention problems.

Concernedly, survey \#1 results showed a diverging opinion between industry and students. In general, students focused on topics related to the science of space such as physics, mathematics, astronomy, and aerodynamics. However, industry responses illustrated a split focus between the sciences such as; propulsion, orbital science, and propellants against more operation and support topics like management, testing facilities, and project management. This was a fundamental difference in expectations of a commercial space program and was noted that it would require considerable effort from the teaching staff to build bridges for the students between their expectations and industry needs.

Survey \#2 results showed a closer relationship between students and industry, though there were still substantial differences. Of the 25 topics listed on survey \#2, there were five topics where there was a three point, or higher difference, in ranking between students and industry. Those areas were: orbital and launch mechanics, rocket separation systems, ignition types, clean rooms and industry leaders. In all cases, except clean rooms, students felt these topics were more important than industry. Of the four, only clean rooms received a ranking greater than 4.0 by either students or industry. 


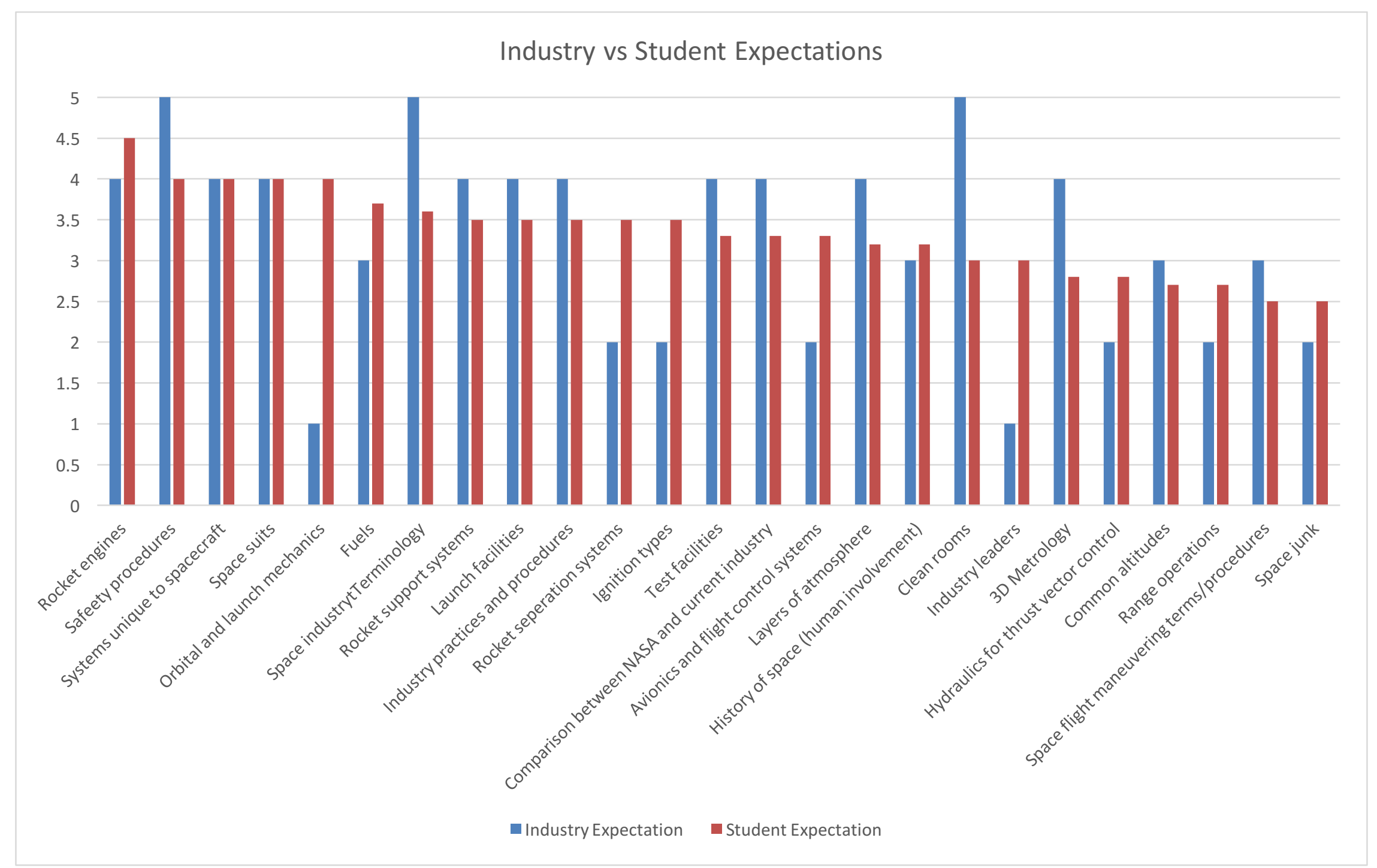

Figure 3. Comparison of topic ratings between industry and students 


\section{Areas of consensus}

Though the surveys showed many areas of differences between students and industry, they also provided areas of consensus. These were seen as potential building blocks for a commercial program. Table 5 listed the topics that were ranked 4.0 or higher on a scale of 0.0 to 5.0. These were the most important topics to both industry and students and provided the greatest alignment. There were four topics that appeared on both lists. Those areas are rocket engines, systems unique to spacecraft, safety procedures, and space suits. Also, four topics total obtained a score of 4.5 or higher among either industry or students. Those topics included: safety procedures, clean rooms, space industry terminology, and rocket engines.

Table 5. Topics rated 4.0 or higher from industry representatives and students

\begin{tabular}{|c|c|}
\hline \multicolumn{2}{|c|}{ Items ranked 4.0 or higher } \\
\hline Industry & Student Expectations \\
\hline Rocket engines & $*$ Rocket engines \\
\hline Systems unique to spacecraft & Systems unique to spacecraft \\
\hline$*$ Safety procedures & Space suits \\
\hline Space suits & Orbital and launch mechanics \\
\hline$*$ Clean rooms & \\
\hline *Space industry terminology & \\
\hline Test facilities & \\
\hline Comparison between NASA and current industry & \\
\hline Industry practices and procedures & \\
\hline Launch facilities & \\
\hline Layers of atmosphere & \\
\hline Rocket support systems & \\
\hline 3D Metrology & \\
\hline
\end{tabular}

* topics ranked 4.5 or higher

\section{Other sources}

Other research in this area was limited, but there are two other studies that provided additional insight into industry needs. A study by Brent Vlasman (2014), found seven subject areas important to the training of technicians of reusable launch vehicles.

- Rocket Propulsion

- Aviation Maintenance

- Electronics/Electrical Systems

- Mechanical Systems

- Engineering

- Project Management

- Aerodynamics 
Yash Bipinchandra Mehta (2013), found yet another list of most important topics. His top ten list included:

- Spacecraft Systems

- Propulsion

- Orbits

- Space Policy and Law

- Satellite Applications

- Life Support Systems

- Commercial Space Programs

- Space Radiation

- Microgravity

- Space History

Both of these studies surveyed industry professionals to find their final list of most important topics. The consensus among the studies was not available at the time of this study, and there were multiple reasons for this. One example is the nascent nature of the industry, and as such, it does not yet truly understanding its needs. Additionally, each study surveyed "industry professionals", but it is not clear whether or not the professionals of each study have equivalent functions and thus, may see different needs.

Regardless, of the addition of additional results, each study does provide some insight into the needs of the industry at this time and should be considered before building a new curriculum. Further research may find these results are strengthened or weakened, or more likely, split up into requirements for different focused areas such as management, production, or support.

\section{Further research}

This research is just the first step in defining expectations for a new program and is not expected to be complete in and of itself. The needs of industry are complex and need more indepth examination. Understanding requirements and their focus areas in greater detail could reconcile the different results from multiple studies.

Curriculum needs should be separated into groups to provide differentiation between the programs. The requirements for those in management, support, and production are different, and should have different curriculum outcomes.

Additionally, further probing on the meaning of the topics is needed to better understand the results. For instance, this survey combined a number of topics under "systems unique to spacecraft". Gaining greater granularity for understanding exactly what that means is vital to the graduation of successful students. Understanding the connection between student engagement and retention with reference to commercial space programs is fundamental to a successful program. What topics are critical to cover for students to remain and thrive in a commercial space program? 
Additionally, a limitation of this research is the limited number of industry participants. Effort towards expanding the subject pool is needed to obtain higher industry-wide confidence in the results.

\section{Conclusion}

At first blush, it would appear that the topical areas of study in the Mehta (2013) study differ substantially from the expectation topics given in this paper. In reality, there are a number of overlap areas, and there is no disagreement by the current authors with the validity of the topical areas in the Mehta (2013) work. The difference lies in the intent of the work in the current study. The topic of expectations from students and current industry personnel have been chosen as the basis for this study, in order to define concepts regarding specific knowledge at a detail level. The focus on "expectations" in the current study is to gather information on topics related to daily hands-on operations.

This approach was taken for two reasons. Historically, when industrial representatives have been asked about relevant topics for commercial space education, the responses generated have been generic and high level. These responses have produced topics that have been more overall educational in nature and less practitioner. The purpose of a study that looked at expectations is to attempt to find more practitioner level topics. The concept is to build on a study such as the Mehta (2013) study and to find out what topics should be developed for hands-on study, and topics that would be of immediate use to a college graduate walking in the door of a commercial space company for that graduate's first job. The generic philosophical underpinnings of the expectations study is that of the question, what things do people in the space industry 'just know' as a function of being a professional? What vocabulary, what processes, what technological concepts are just assumed to be automatically a part of people "in the business"? The study of expectations has proved to be a good reflection of these low-level concepts.

When comparing the Mehta (2013) study to the current expectations study, it is easy to envision a commercial spacecraft program that delivers information on all of the Mehta (2013) topics, and then uses the topics in the expectations study as those used for hands-on learning or project learning in a laboratory environment. So, propulsion for example in Mehta (2013) is envisioned as being an education in the theory and application of various propulsion technologies, while in the current study "rockets" takes that same concept and focuses it down to specifics of propulsion components, materials, serviceable components, etc. Similarly spacecraft systems in Mehta (2013), again, provides an education in the theory and application of various spacecraft systems, the current study on spacecraft systems takes that same concept and focuses it down to specifics of system components, materials, serviceable components, etc. Other elements in the current study follow the same conceptual vein; look at these concepts at a high level, educations vantage point, but then drill down on specifics to a detailed, operational level. From this perspective, the Mehta (2013) study and the current study dovetail well together, and the current authors concur that Mehta (2013) provides an excellent selection of topical information. The non-overlapping concepts in this study, are areas where more detailed, practitioner level knowledge and skills are to be developed. Again, the desire of the current authors is to determine various areas for study of detailed, day-to-day knowledge concepts to prepare the graduate to be able to rapidly understand the activities on the manufacture, assembly, handling, and operations of spaceflight hardware. The perspective of an 
"expectations" survey has proved to be the most effective direction for getting this kind of information from the commercial operators to date by these authors.

The purpose of gathering expectations from students serves multiple purposes. When establishing a program it is important to know if there is congruence between what the students believe they are going to learn, and what is actually taught, and it provides perspective on how the information is to be presented. Additionally, where the topics overlap with industry expectations, it provides relevance to the students for the instruction being delivered, as well as an acceptance of the instructional personnel as having congruent values with the industry.

The commercial space industry has a need for technicians and technologists, and this provides an opportunity for technology and engineering technology schools to develop programs. The first step in any program is to develop an understanding the requirements and the niche the graduate must fill, after which a program can be built. The needs analysis must come first. Following that, a successful program can be developed that can serve and shape an industry, and provide excellent career opportunities for their students. 


\section{References}

Aviation Week Network. (2016). Aviation week executive intelligence special report. C. Sands

Captain, T, (2016). 2016 Global aerospace and defense sector outlook: Poised for a rebound. Deloitte Touche Tohmatsu Limited: London, UK

Captain, T, \& Hanley, T. (2017). 2017 Global aerospace and defense sector outlook: Growth prospects remain upbeat. Deloitte Touche Tohmatsu Limited: London, UK

Federal Aviation Administration. (2014). The Annual Compendium of Commercial Space Transportation: 2014. Washington D.C.

Federal Aviation Administration. (2016). The Annual Compendium of Commercial Space Transportation: 2016. Washington D.C.

Gates, D., Mayor, T., \& Gampenrieder, E. L. (2016). Global Aerospace and Defense Outlook. KPMG International: Amstelveen, Netherlands.

Mehta, Y. B. (2013). Incorporating industry needs into the development of an undergraduate degree in commercial space operations (Order No. 1548211). Available from ProQuest Dissertations \& Theses Global. (1467452393). Retrieved from http://search.proquest.com.ezproxy.lib.purdue.edu/docview/1467452393?accountid= $\underline{13360}$

United States Government Accountability Office (2014). Aviation workforce: Current and future availability of aviation engineering and maintenance professionals. Washington D.C.

U.S. Bureau of Labor Statistics (2017). Retrieved from https://www.bls.gov/ooh/architecture-and-engineering/aerospace-engineering-andoperations-technicians.htm

Vlasman, B., A. (2010). Industry perspectives on reusable launch vehicle technicians. Masters Abstracts International (49-01).

Zillman, C., (2013). America's defense industry is going grey. Fortune.com, 1. Retrieved from http:// fortune.com/2013/11/12/americas-defense-industry-is-going-gray/ 


\section{Appendix A}

\section{Survey \#1}

This survey is voluntary and please do NOT list your name or any personal information. The purpose of this survey is to measure a level of interest and knowledge of students in a current undergraduate Aeronautical Engineering Technology class for the Space industry.

A) Please rate your personal experience about space/space technology.

1. I have no prior knowledge about space/space technology

2. I understand some concepts about space/space technology, but have not worked/studied with any space related classes

3. I have studied some aspects about space/space technology in a classroom environment or from personal interest

4. I regularly read space related publications, have participate on a space related class project, and/or study space related materials

5. I have had an internship/job with a company involved in space and/or have worked with space material on a university level class project

B) Below, list as many subjects as you can that you feel you should know in order to succeed in the space industry.

1.

2.

3.

4.

5.

6.

7.

C) If you were able to take a familiarization course about space and space technologies, would you be interested in (please circle one answer)

1. Attending two lectures and one 50 min. activity based lecture

2. Attending a lecture class three times a week

3. Attending two lectures and one lab a week 


\section{Appendix B}

\section{Survey \#2}

Please do NOT list your name or any personal information. The purpose of this survey is to measure a level of interest and knowledge of students in a current undergraduate Aeronautical Engineering Technology class for the Space industry.

Below are 25 topics related to space and the space industry. Using a scale of $0-5$ (0 being not important and 5 being very important), rate what you feel is the importance of each topic for the space industry.

\begin{tabular}{|l|l|}
\hline & \\
\hline Launch Vehicles & \\
\hline Space Industry Terminology & \\
\hline Rocket Support Systems $(0-5)$ \\
\hline Clean Rooms & \\
\hline Rocket Engines & \\
\hline Launch Facilities & \\
\hline Safety Procedures & \\
\hline Space Suits & \\
\hline Layers of Atmosphere and Meteorology & \\
\hline Rocket Separation Systems & \\
\hline Space Flight Maneuvering terms/procedures & \\
\hline Test Facilities & \\
\hline 3D Metrology & \\
\hline Fuels & \\
\hline Industry Practices and Procedures & \\
\hline NASA & \\
\hline Orbital and Launch mechanics & \\
\hline Common altitudes & \\
\hline Ignition types & \\
\hline History of Space (human involvement) & \\
\hline Range Operations & \\
\hline Hydraulics for Thrust Vector Control & \\
\hline Space Junk & \\
\hline Avionics and Flight Control Systems & \\
\hline Industry Leaders & \\
\hline
\end{tabular}

